\title{
HEALTH PROFESSIONAL COLLABORATION TO IMPROVE PATIENT OUTCOME: A SYSTEMATIC REVIEW
}

\author{
Sigit Sugiyanto' ${ }^{1)}$, Atik Nurwahyuni ${ }^{2)}$ \\ 1)Masters Program Hospital Management, Faculty of Public Health, \\ Universitas Indonesia \\ 2)Faculty of Public Health, Universitas Indonesia
}

\begin{abstract}
Background: Hospital readmission within 30 days of discharge represents a potentially preventable adverse outcome. Hospital readmission reduction program may be proposed to reduce readmission rate. Prior studies have shown that collaboration of health professionals might be able to lower readmission. This study aimed to review systematically health professional collaboration to reduce hospital readmission.

Subjects and Method: This was systematic review conducted by searching articles from 2014 to 2019, from the Pro Quest database. The keywords were "interprofessional", "clinical rounding", "readmission", and "bedside rounding". The inclusion criteria were English language, open access journal, cohort study, and experiment study. After review process, 9 articles were included in this review.

Results: Collaboration of the health care professional care team could enhance health care provision for patients. This collaboration could improve the quality of service and prevent readmission in hospital.

Conclusion: Collaboration of the professional care team can improve the quality of service and prevent readmission in hospital.

Keywords: communication, collaboration, professional care team, quality of service, readmission, hospital

\section{Correspondence:}

Sigit Sugiyanto. Masters Program Hospital Management, Faculty of Public Health, Universitas Indonesia, Depok, West Java. Email: sigit.md81@gmail.com Mobile: +6281513234567 .
\end{abstract}

The $6^{\text {th }}$ International Conference on Public Health

Best Western Premier Hotel, Solo, Indonesia, October 23-24, 2019 | 280

https://doi.org/10.26911/the6thicph.04.42 